\title{
Zastosowanie kamery termowizyjnej w badaniach nieniszczących wybranych elementów kolejowego układu hamulcowego
}

\author{
The use of thermal imaging cameras in nondestructive testing \\ of selected elements of the brake system
}

\section{Streszczenie}

Skuteczność procesu hamowania w pojazdach szynowych w dużej mierze zależy od doboru elementów pary ciernej tarcza hamulcowa - okładzina cierna. Niestabilna praca układu hamulcowego jest spowodowana zmianami w przebiegu współczynnika tarcia, w szczególności jego obniżenia w procesie hamowania. Celem artykułu jest przedstawienie możliwości zastosowania kamery termowizyjnej w ocenie stanu pary ciernej hamulca tarczowego. W artykule zwrócono uwagę na trzy aspekty oceny stanu. Pierwszy związany z identyfikacją mikropęknięć na powierzchni tarczy. Drugi aspekt związany z rozkładem nacisków na tarczy hamulcowej oraz ostatni związany rozkładem temperatury na powierzchni okładzin ciernych.

Słowa kluczowe: kamera termowizyjna; hamulec tarczowy; pojazd szynowy

\begin{abstract}
The reliability of the operation of the braking system of the rail vehicle depends to a large extent on the cooperation of the brake components forming a pair of friction e.g. brake disc-friction pad. Work instability arises by the occurrence of instantaneous changes to the coefficient of friction, which affects the lower efficiency of the braking process. The purpose of the article is to present the possibility of using thermal imaging cameras in the assessment of a friction gear disc brakes. The article highlighted three aspects of the state assessment. The first, associated with the identification of microcracks on the surface of the disk. The second aspect that is associated with the pressure distribution on the brake disc and the last associated temperature distribution on the surface of the friction pads.
\end{abstract}

Keywords: IR camera; disc brake; rail vehicle

\section{Metodyka badań termowizyjnych}

Badania z zastosowaniem kamery termowizyjnej przeprowadzono na stanowisku hamulcowym do badań układów hamulcowych pojazdów szynowych. Do badań wykorzystano tarcze hamulcowe o średnicy 590 i $640 \mathrm{~mm}$ oraz okładziny cierne typu FR20.H.2. Podczas rejestracji parametrów hamowania, dodatkowo przed tarcza hamulcową zainstalowano kamerę termowizyjną FLIR e60.

\section{Ocena stanu powierzchni ciernej tarczy hamulcowej}

Długotrwała eksploatacja tarczowych układów hamulcowych wykazała, że przy hamowaniach z dużych prędkości lub hamowaniach w krótkich odstępach czasu, dochodzi
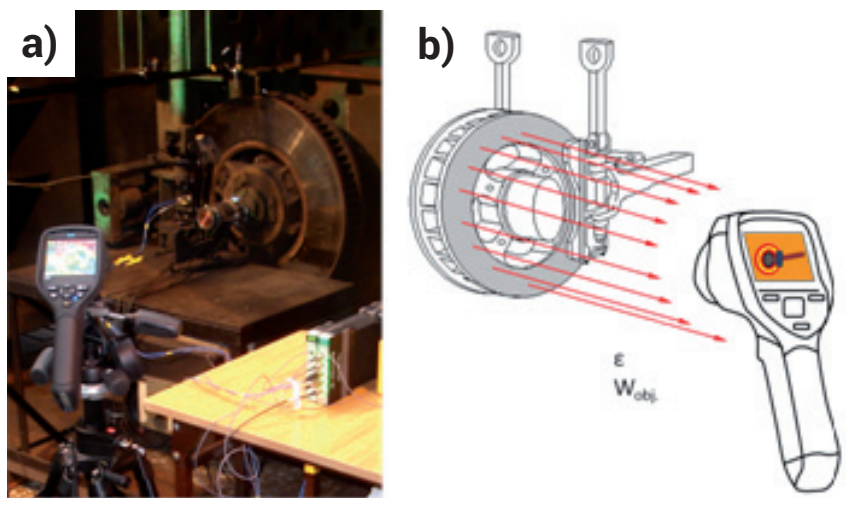

Rys. 1. Metodyka badań termowizyjnych: a) widok tarczy hamulcowej i kamery termowizyjnej, b) schemat promieniowania emitowanego przez tarczę do kamery

Fig. 1. Methodology of thermal research: a) view of the brake disc and camera IR, b) a diagram of radiation emitted by the disc to the camera

Dr inż. Wojciech Sawczuk, dr inż. Jakub Kowalczyk, dr inż. Dariusz Ulbrich - Politechnika Poznańska.

Autor korespondencyjny/Corresponding author: dariusz.ulbrich@put.poznan.pl 
do przyspieszonego zużycia powierzchni ciernej tarczy [1]. Na powierzchni tarczy pojawiają się mikropęknięcia, które rozrastają się promieniowo przy kolejnych hamowaniach.
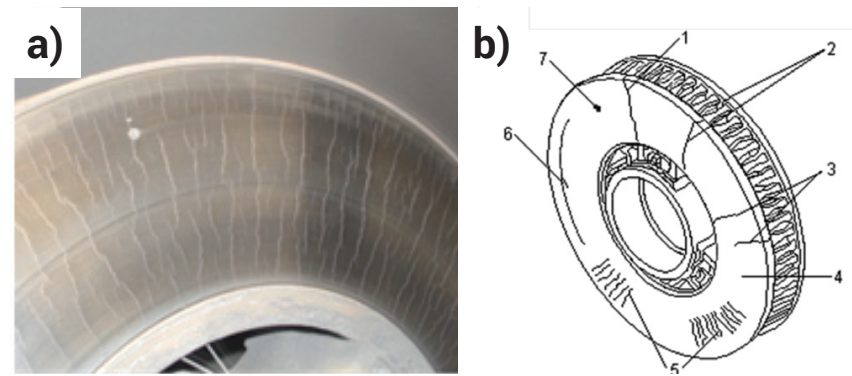

Rys. 2. Rodzaje pęknięć na powierzchni tarczy hamulcowej: a) widok pęknięć powierzchniowych, b) 1 - pęknięcie jednostronne na całej szerokości pierścienia, 2 - pęknięcie obustronne na całej szerokości pierścienia, 3 - pęknięcie na części szerokości pierścienia, 4 - wklęsłości, 5 - pęknięcie powierzchniowe, 6 - rowki, 7 - wykruszenia

Fig. 2. Types of cracks on brake disc surface: a) view of surface cracks, b) 1 - single-sided crack on the whole disc brake breadth, 2 - double-sided crack on the whole disc brake breadth, 3 - crack on a part of disc brake breadth, 4 - concavities, 5 - surface cracks, 6 - grooves, 7 - spallings

Na rysunku 2 przedstawiono na podstawie [2] typowe uszkodzenie powierzchni ciernej tarczy hamulcowej. Jednak obserwacja wagonów z tarczowym układem hamulcowym wykazała, że pęknięcia powierzchniowe (mikropęknięcia) są najliczniejszym i najczęściej występującym rodzajem uszkodzeń tarcz hamulcowych. Na rysunkach 3 i 4 przedstawiono obraz cyfrowy oraz termowizyjny dwóch tarcz hamulcowych (nowej oraz zużytej).
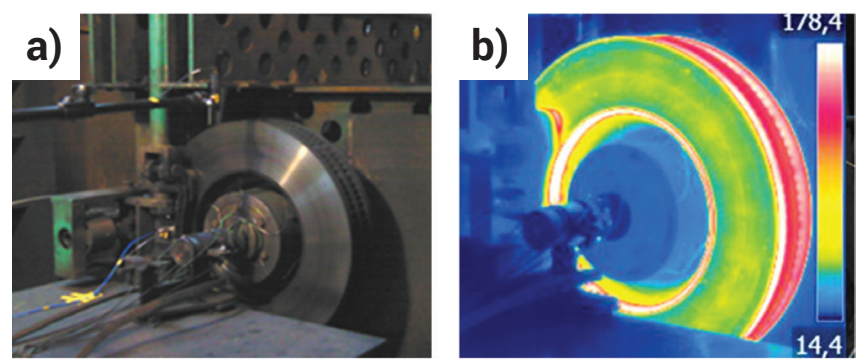

Rys. 3. Widok nowej tarczy hamulcowej: a) obraz cyfrowy, b) obraz termowizyjny

Fig. 3. View of the new brake disc: a) scan, b) thermal image
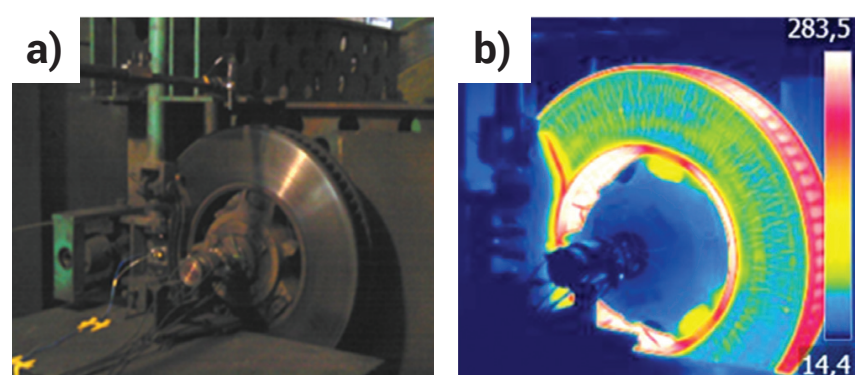

Rys. 4. Widok zużytej tarczy hamulcowej: a) obraz cyfrowy, b) obraz termowizyjny

Fig. 4. View of the wear brake disc: a) scan, b) thermal image

\section{Ocena kontaktu okładzin ciernych z tarczą hamulcową}

Kolejnym zastosowaniem kamery termowizyjnej jest ocena współpracy okładzin ciernych z tarcza hamulcową, co również autorzy przedstawili w [3]. a)

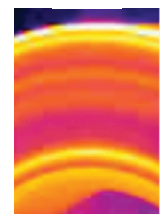

a)

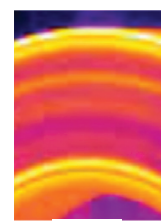

a)

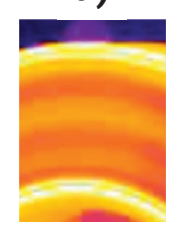

b)

b)

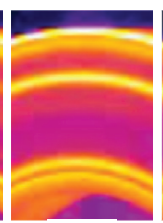

c)

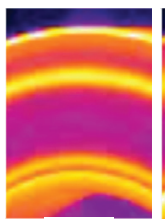

c)

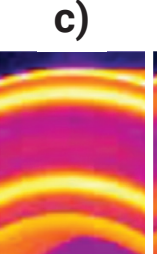

d)

e)

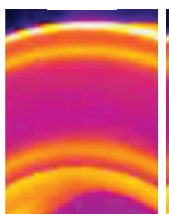

d)

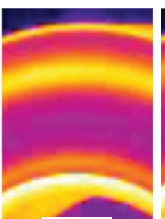

d)

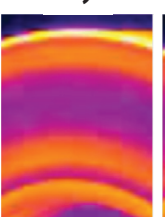

e)
Rys. 5. Obraz termowizyjny tarczy hamulcowej w czasie hamowania z prędkością: 1) v = $120 \mathrm{~km} / \mathrm{h}$, a) po 4 sekundach hamowania, b) po 9 sekundach, c) po 16 sekundach, d) po 20 sekundach, e) po 28 sekundach, 2) v=160 km/h, a) po 4 sekundach, b) po 8 sekundach, c) po 14 sekundach, d) po 29 sekundach, e) po 44 sekundach, 3) v = $200 \mathrm{~km} / \mathrm{h}$, a) po 2 sekundach, b) po 4 sekundach, c) po 15 sekundach, d) po 43 sekundach, e) po 62 sekundach

Fig. 5. Thermal image of the brake disc during braking from a speed of: 1) $v=120 \mathrm{~km} / \mathrm{h}$, a) after 4 seconds, b) after 9 seconds, c) after 16 seconds d) after 20 seconds e) after 28 seconds, 2) $v=160 \mathrm{~km} / \mathrm{h}$, a) after 4 seconds, b) after 8 seconds, c) after 14 seconds, d) after 29 seconds, e) after 44 seconds, 3) v=200 km/h, a) after 2 seconds, b) after 4 seconds c) 15 seconds d) after 43 seconds, e) after 62 seconds

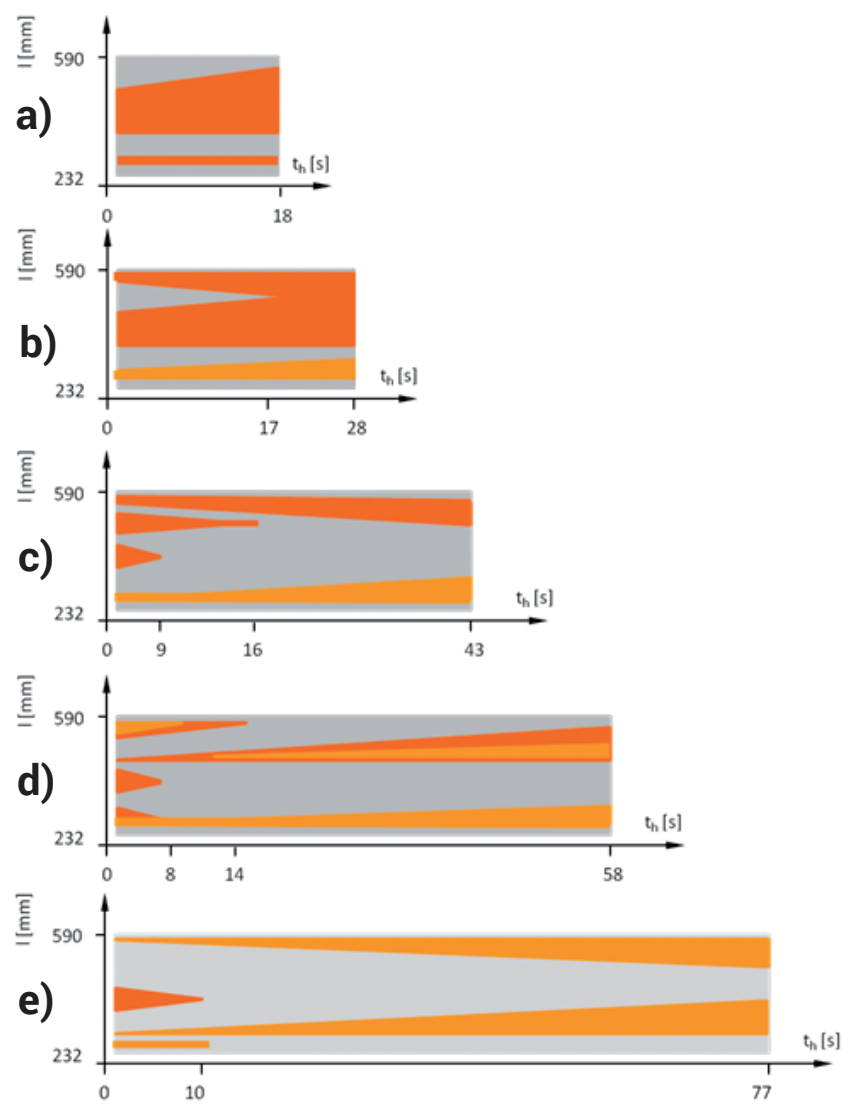

Rys. 6. Modele rozkładu nacisków okładziny do tarczy na podstawie badań termowizyjnych dla hamowania z prędkości: a) $50 \mathrm{~km} / \mathrm{h}$, b) $80 \mathrm{~km} / \mathrm{h}$, c) $120 \mathrm{~km} / \mathrm{h}$, d) $160 \mathrm{~km} / \mathrm{h}$, e) $200 \mathrm{~km} / \mathrm{h}$

Fig. 6. Pressure distribution models of the pad to the brake disc based on the results of the thermal tests for braking speeds: a) $50 \mathrm{~km} / \mathrm{h}$, b) $80 \mathrm{~km} / \mathrm{h}$, c) $120 \mathrm{~km} / \mathrm{h}$, d) $160 \mathrm{~km} / \mathrm{h}$, e) $200 \mathrm{~km} / \mathrm{h}$ 
W czasie badań termowizyjnych nagrywano filmy z całego procesu hamowania, przy automatycznym ustawieniu zakresu temperatury w kamerze. Metodą maksymalnej temperatury, stwierdzono o rzeczywistym kontakcie okładziny z tarczą hamulcową. Na rysunku 5 przedstawiono wybrane fragmenty obrazu termowizyjnego tarczy hamulcowej w różnych odstępach czasu hamowania. Analizując zarejestrowane filmy na kamerze termowizyjnej - opracowano modele rozkładu nacisków do tarczy, co przedstawia rysunek 6.

\section{Ocena rozkładu temperatury okładzin ciernych hamulca tarczowego}

Kolejnym etapem badań był ocena jakościowa rozkładu temperatury na powierzchni okładzin ciernych po serii 15 hamowań $z$ prędkości $v=50,80,120,160$ i $200 \mathrm{~km} / \mathrm{h}$ z naciskiem okładziny do tarczy $\mathrm{N}=25 \mathrm{kN}$. Na rysunku 7 przedstawiono rozkład temperatury na okładzinach ciernych o grubości 35 (okładzina nowa), 25 i 15 mm (okładziny zużyte).
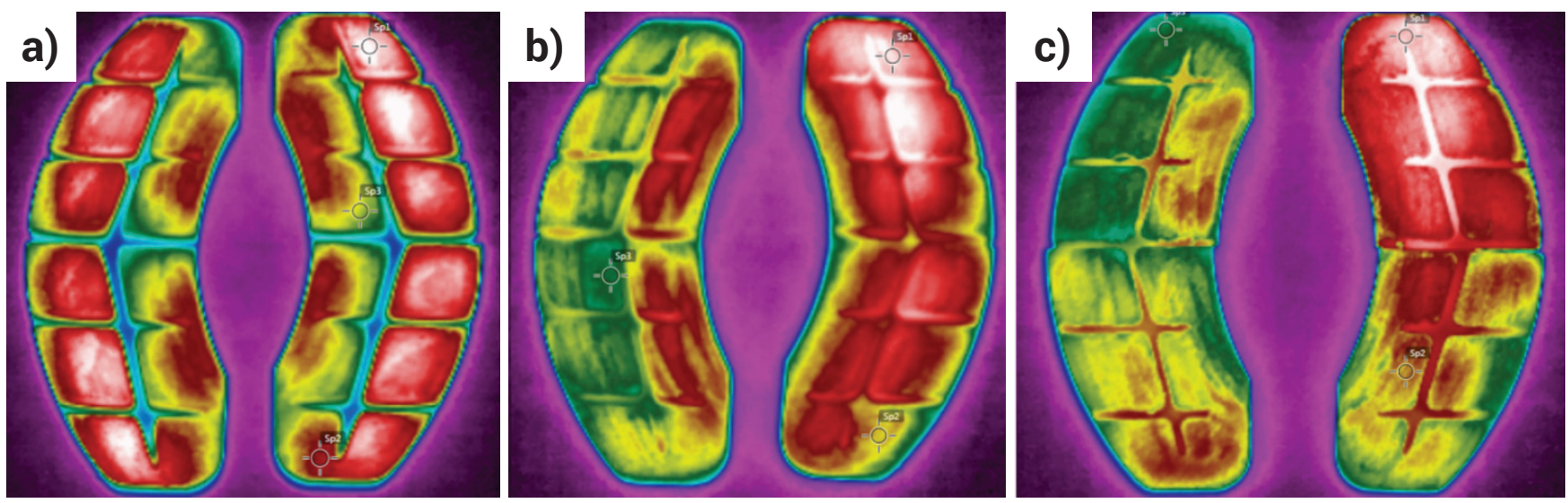

Rys. 7. Obraz termowizyjny z okładzin ciernych o grubości: a) $35 \mathrm{~mm}$, b) $25 \mathrm{~mm}$, c) $15 \mathrm{~mm}$

Fig. 7. Thermal image of brake pads with thickness: a) $35 \mathrm{~mm}$, b) $25 \mathrm{~mm}$, c) $15 \mathrm{~mm}$

\section{Wnioski}

Na podstawie przeprowadzonych badań termowizyjnych na stanowisku hamulcowym do hamulca tarczowego, stwierdzono:

- Kamerą termowizyjną możliwa jest ocena stanu powierzchni ciernej tarczy hamulcowej w zakresie identyfikacji mikropęknięć.

- Hamowania z małych prędkości ( $v=50$ i 80 km/h) powodują najlepszy rozkład nacisków okładziny do tarczy hamulcowej a czas hamowania wpływa na poprawę rozkładu, przez co większa części powierzchni okładziny styka się z tarczą hamulcową.

- Hamowania z dużych prędkości ( $v=120,160$ i 200 km/h) powodują, że w pierwszych sekundach hamowania kontakt okładziny z tarczą hamulcową jest trzy- lub czteropunktowy tworząc pierścienie cieplne na tarczy hamulcowej, które następnie łączą się $\mathrm{w}$ dwa pierścienie.

- Okładziny zużyte względem okładzin nowych wykazują gorszy kontakt z tarczą hamulcową, co może mieć związek ze zmniejszeniem ich sztywności i większą podatnością do odkształceń.

Projekt jest finansowany ze środków Narodowego Centrum Badań i Rozwoju, program LIDER V, umowa nr LIDER/022/359/L-5/13/NCBR/2014.

\section{Literatura}

[1] M.Sorochtej:Kształtowanie jakości zespołu ciernego hamulca tarczowego, Przegląd Kolejowy 1/94.

[2] Rail Consult Gesellschaft für Verkehrsberatung mbH: Wagon osobowy Z1 02, układ jezdny - tom 2, Dokumentacja Techniczno-Ruchowa.
[3] S. Paniera, P.Dufrénoy, D. Weichert: An experimental investigation of hot spots in railway disc brakes, WEAR 256 (2004), 764-773.

\section{Zapraszamy Państwa do odwiedzenia i polubienia naszego profilu na Facebooku}

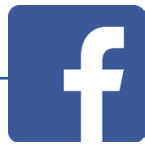

